International Review of Research in Open and Distributed Learning Volume 16, Number 4

October - 2015

\title{
Personal Spaces in Public Repositories as a Facilitator for Open Educational Resource Usage
}

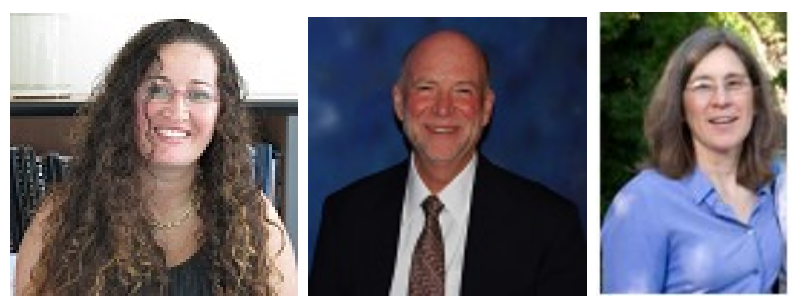

Anat Cohen, Sorel Reisman, and Barbra Bied Sperling Tel Aviv University, California State University

\begin{abstract}
Learning object repositories are a shared, open and public space; however, the possibility and ability of personal expression in an open, global, public space is crucial. The aim of this study is to explore personal spaces in a big learning object repository as a facilitator for adoption of Open Educational Resources (OER) into teaching practices and to gain more insight into different types of OER user behaviors by analyzing the users' behaviors in the Bookmark Collection of MERLOT (a personal space, formerly known as Personal Collection), along with other community activities in that repository: writing comments and peer reviews, as well as sharing learning materials, learning exercises, and contents that were built with the content builder. In addition, using a data mining methodology, most active Bookmark Collection contributors $(\mathrm{N}=507)$ were classified into clusters of users with the same patterns of activity. Three clusters resulted, which gave insights into different types of contributor behavior. Furthermore, it was found that personal spaces are applicable for a variety of uses with diverse goals. Members create personal spaces for their own use, while allowing others to view and copy; or for other users. Personal space encourages the reuse of learning materials and enables the construction of unique learning processes that suit the learner's needs. They may offer the possibility of personalizing public repositories and promoting the reuse of OER.
\end{abstract}

Keywords: Open Educational Resource (OER); Personal Spaces; Learning Objects Repositories 


\section{Introduction}

The current global trends of sharing and retrieving Open Educational Resources (OER) provides a strategic opportunity to improve the quality of education as well as facilitate policy dialogue, knowledge sharing, and capacity building (Downes, 2007; Bonk, 2009; Hilton, Wiley, Stein, \& J ohnson, 2010; Hilton \& Wiley, 2011; Hart, Chetty, \& Archer, 2015). However, despite the many advantages inherent in OER (Downes, 2007), the level of OER adoption into common teaching practices remains quite low (De Liddo, 2010; Murphy, 2013) due to a variety of barriers and challenges (Cannell, Macintyre, \& Hewitt, 2015; Bernstein, 2014; Pirkkalainen \& Pawlowski, 2013). Furthermore, some have argued that OER are still mainly created in the developed World (Butcher \& Hoosen, 2012).

OER are commonly stored, used, adapted, remixed and shared within learning object repositories (Clements, Pawlowski, \& Manouselis, 2015), which are a shared, open, and public space; however, the possibility and ability of personal expression in these repositories is crucial. The aim of this study is to explore personal spaces in a big learning object repository as a facilitator for adoption of OER into teaching practices and to gain more insights into different types of OER user behaviors by analyzing users' behaviors in the Bookmark Collection of MERLOT (a personal space, formerly known as personal collection), along with other community activities in the repository, such as: writing comments, peer reviewing, submitting learning exercises, and content builder materials. In addition, using a data mining methodology, the Bookmark Collection users were classified into clusters based on their activity.

The Bookmark Collection is a module that members can access easily to use for specific purposes, classes, or topics. The owner of the Bookmark Collection can annotate each collection to easily explain its purpose, a pedagogical approach, and if it relates to a specific course. This study is an initial step toward understanding the experience of the repository members who adopt these Bookmark Collections, along with understanding the advantages of these collections and their instructional value. This study provides data regarding the usage rate of Bookmark Collections and describes the extent of materials reused through them; it profiles the users and describes the extent of their use and aims.

\section{Theoretical Framework}

In today's knowledge society, knowledge and skills play a major role in reducing poverty and promoting growth. The future of countries is increasingly dependent on the knowledge, skills, and resourcefulness of their people. Education is of vital importance in the knowledge society, as a source of basic skills, a foundation for development of new knowledge and innovation, and an engine for socio-economic development. It is, therefore, a critical requirement in creating

This work is licensed under a Creative Commons Attribution 4.0 International License. 
knowledge societies that can stimulate development, economic growth, and prosperity (Butcher, 2010).

The importance of Open Educational Resources (OER) to education and knowledge societies has been widely documented and demonstrated recently. The continuous growth of learning resources available on-line (The Directory of Open Access Repositories - OpenDOAR, 2015) supports the trend of openness of materials and their availability on the Web as OER. The term OER is the results of a Spring 2002 meeting held at UNESCO, and organized with support of WCET and the William and Flora Hewlett Foundation (Wiley, 2007). OER are defined as "technology-enabled, open provision of educational resources for consultation, use and adaptation by a community of users for non-commercial purposes" (UNESCO, 2002). OER refers to educational resources that are freely available over the Web or the Internet for use by educators and learners without an accompanying need to pay royalties or license fees (Butcher $\&$ Hoosen, 2012). They are predominantly used by teachers and educational institutions to support course development, but they can also be used directly by students. OER include learning objects such as lecture material, references and readings, simulations, experiments and demonstrations, as well as syllabi, curricula, and teachers' guides. OER are a relatively new phenomenon, which may be seen as part of a larger trend toward openness in education, including more well-known and established movements such as Open Source Software (OSS) and Open Access (OA) (Hylén, 2006).

Institutions and organizations such as MIT, Carnegie Mellon, Berkeley, Connexions Globe, The National Science Digital Library, MERLOT and others are offering a wide range of free learning materials online in different configurations, such as: free educational courses (e.g. MIT open courseware) and textbooks; repositories of learning objects (e.g. Globe and MERLOT) that manage access to reusable learning content, as it has been defined by several authors (Monge, Ovelar \& Azpeitia, 2008); open source learning management systems (e.g. Moodle) and open software tools. These are offered openly and for free, contrary to the policy that was acceptable by universities and educational institutions not long ago (Abelson, 2008; Malloy \& Hanley, 2001; Taylor, 2007).

The concept of OER has gained significant currency around the world, becoming a subject of heightened interest in policy-making and in institutional circles as many people and institutions explore its potential to contribute to improved delivery of education and its ability to tackle some of the key problems facing education systems (Butcher \& Hoosen, 2012). For the first time in human history we have the tools to enable everyone to attain all the education they desire (Wiley, Green, \& Soares, 2012). The current global trends of sharing and retrieving materials, through which multiple content developers offer their learning materials to the public free of charge, provide a strategic opportunity to improve the quality of education as well as facilitate policy dialogue, knowledge sharing, and capacity building. OER provide a significant opportunity to share both content knowledge and pedagogical practice. However, Hilton, Wiley, Stein \&J ohnson 
(2010) claim that "it is important to recognize that 'openness' is not a dichotomous concept; rather, there is a continuum of openness. Designers of OER should decide early on whether they wish to facilitate reuse and redistribution only, or if they also want enable revising and remixing. Those who wish to facilitate reuse and remix of OER should license their works accordingly (p.43)." Furthermore, Hilton, Lutz, \& Wiley (2012) claim that an important element of OER is the permission to use the materials in new ways, including revising and remixing them. However, the revision and remix rates for OER are relatively low and not always encouraged by the institution, both within higher education institutions and other informal educational systems.

\section{Learning Object Repositories}

Learning Objects (LOs) are often defined as digital entities that can be used and reused in the process of learning and education and are considered by many as the cornerstones for the widespread development and adoption of e-learning initiatives (Cechinel, Sanchez-Alonso \& Garcia-Barriocanal, 2011). LOs are elements of a new type of computer-based instruction grounded in the object-oriented paradigm of computer science. Object-orientation highly values the creation of components (called "objects") that can be reused (Dahl \& Nygaard, 1966) in multiple contexts. This is the fundamental idea behind LOs: instructional designers can build small (relative to the size of an entire course) instructional components that can be reused a number of times in different learning contexts. Additionally, LOs are generally understood to be digital entities deliverable over the Internet, meaning that any number of people can access and use them simultaneously (as opposed to traditional instructional media, such as an overhead or video tape, which can only exist in one place at a time). Those who incorporate LOs can collaborate on and benefit immediately from new versions. These are significant differences between LOs and other instructional media that have existed previously (Wiley, 2000). Friesen (2009) points out modularity as a technological and design attribute for the object and its content, with emphasis on the "self-contained," "building block," or "object-oriented" nature of the technology.

LO repositories are systems that enable the storage, discovery, and retrieval of meta-data and/ or electronic learning objects stored at a local or distributed level (The J ORUM Team, 2006). More specifically, a Learning Object Repository (LOR) is a system that manages access to reusable learning content, as it has been defined by several authors (Monge, Ovelar \&Azpeitia, 2008).

\section{MERLOT - A Learning Object Repository}

MERLOT is a portal that is connected to multiple digital learning object repositories (Malloy \& Hanley, 2001). It contains only the object metadata and allows access to learning materials hosted in the connected repositories. The objects stored in these repositories are characterized according to international standards for learning objects metadata (LOM). The metadata fields describe the object and the possibilities for its use, so that objects may be located using keywords, retrieved, and examined to see whether they suit learners' needs (Cohen, Shmueli \& Nachmias, 2011). The MERLOT repository provides access to learning materials, learning exercises, comments, 
Bookmark Collections (personal spaces), and Content Builder Web pages, all designed to enhance the teaching experience of an online learning material. The learning materials are categorized into 18 different learning material types. A large selection of materials in MERLOT also has assignments and comments attached to them. It is additionally possible to add any material to a personal space (Bookmark Collection), which helps in organizing teaching materials for different purposes.

MERLOT is not only a learning materials repository but it is a free and open online community of resources designed primarily for faculty, staff, and students of higher education from around the world to share their learning materials and pedagogy (J orum, 2006; Reisman, 2009). MERLOT is a leading edge, user-centered, collection of peer reviewed higher education, online learning materials, catalogued by registered members and a set of faculty development support services. MERLOT's strategic goal is to improve the effectiveness of teaching and learning by increasing the quantity and quality of peer reviewed online learning materials that can be easily incorporated into faculty designed courses.

\section{Personal Spaces}

Personal spaces in learning object repositories allow users to construct, preserve and present knowledge in a way uniquely suited to their individual patterns of use by utilizing technological tools to mark materials such as tags, bookmark collections, etc. (Razavi \& Iverson, 2006; Cechinel, Sánchez-Alonso, \& García-Barriocanal, 2011; Qian, 2010). Alongside the many advantages inherent in sharing and integrating materials in a public space, personal spaces are still supported, which allow users self-expression within the learning and creative process. Personal workspaces within open repositories allow the construction of a unique learning process in private spaces that suit the learner's needs. Creators of these learning processes can use materials developed by others and include them in their personal spaces within the repository. At the same time they may transfer learning materials from their personal spaces and into the public space and thus share them with others. It is the decision of the creators whether to make personal use of the new processes, or to distribute them to other users. The building blocks - the learning objects - remain in the public domain, yet the construction of the new process takes place in a personal space.

The MERLOT Bookmark Collection is a Web-based tool which provides personal space for users. It is an online format suitable for large-scale adoption. It is applicable in a variety of uses and can be used by ALL (members and non- members, faculties and students, $\mathrm{k}-12$ teachers, librarians, content developers, etc.), all over the world, free of charge and with no need for special skills and tools other than access to the internet. Consequently, the Bookmark Collection is a highly cost effective approach to supporting instruction and learning processes.

MERLOT Bookmark Collections may offer the stimulating possibility of personalizing public learning object repositories, with the emphasis on the individual. Even though they add a strong 
element of personalization to the system, they still retain the many institutional benefits of learning object repositories.

\section{Methodology and Methods}

\section{Study Aims and Questions}

The aim of this study is to explore personal space as a facilitator for adoption of OER into common teaching practices and to gain more insights into different types of OER user behaviors in public repositories by analyzing users' behaviors in the Bookmark Collection of the MERLOT repository (www.merlot.org), a personal space, formerly known as Personal Collection, along with other community activities in the repository, such as: writing comments, peer reviewing, submitting learning exercises, and content builder materials. The characteristics of Bookmark Collections and their use are examined in order to understand how they can promote the use of OER, enhance pedagogical content knowledge and engage the repository members. In order to provide a wide view of the Bookmark Collection process in MERLOT and benefits to the repository users, the usage rate of Bookmark Collections will be measured and the user profiles and the extent of their use and aims will be described. This study is an initial step toward understanding the experience of the repository members who adopt these personal spaces. Correspondingly, this study provides answers to four questions: (a) What is the extent of Bookmark Collection use; (b) Who are the Bookmark Collection users and what are their characteristics? (c) To what extent were materials retrieved/reused through Bookmark Collections?; and (d) What are the Bookmark Collection uses and aims?

\section{Study Field}

The study was initially conducted on the Bookmark Collections which were cataloged in the MERLOT repository as of J uly 2014 ( $N=20,138$ collections). Subsequently, the study focuses on the 9,802 contributors to these collections.

\section{Method}

The MERLOT repository automatically accumulates a vast amount of data in its server Web-logs. Through Web mining techniques, access to the server database was enabled and data regarding the Bookmark Collections that were cataloged in the MERLOT repository was retrieved. The data regarding the Bookmark Collections was extracted directly from the server Web-logs and was organized in various tables that provide data regarding the Bookmark Collection description, pattern of usage, and Bookmark Collection contributors. For example, the information table provides data regarding the collection ID, title, description (including use and aim), date created/modified, number of materials, creator ID and name; and the creators information table provides data regarding the member ID (the creator), affiliation, discipline, member type, contribution level, number of collections created, number of authored materials, number of peer 
reviews, and comments, etc. The data are extracted from the Web-logs and provide crucial information regarding the collections.

Different statistical analyses were conducted: Descriptive statistics; cluster analysis for classifying the users based on their activity in the personal space and the public space; and One-Way ANOVA for comparing different groups of users.

\section{Results}

This section provides data regarding the usage rate of personal spaces (Bookmark Collections) and describes the user profiles; and the extent of their use and aims, as an initial step toward understanding the activity patterns of the repository members who contributed these Bookmark Collections and subsequently reused OER.

\section{The Usage Rate of Bookmark Collections}

MERLOT has 124,523 members (as of July 8, 2014). Of those, 9,802 members have 2 personal spaces (Bookmark Collections) on average ( $\mathrm{Std}=3.7$ ), and there are a total of 20,816 collections among the following nine disciplines: Arts $(1,045)$; Business $(1,578)$; Education $(3,889)$; Humanities (3,149); Mathematics and Statistics $(1,029)$; Science and Technology $(5,924)$; Social Sciences (1,342); Workforce Development (116); and Academic Support Services $(2,066)$. All collections are shared with the community.

Analysis of Bookmark Collection content, using keywords, was conducted as well. Observation of words used in the Bookmark Collections can be visualized using "words cloud", as shown in Figure 1 (the number of word instances is reflected in the font size of each word). The cloud shows topics related to teaching and learning, assessment, information, technology, etc. in various disciplines, such as science, chemistry, biology, language, history, arts, and music. 


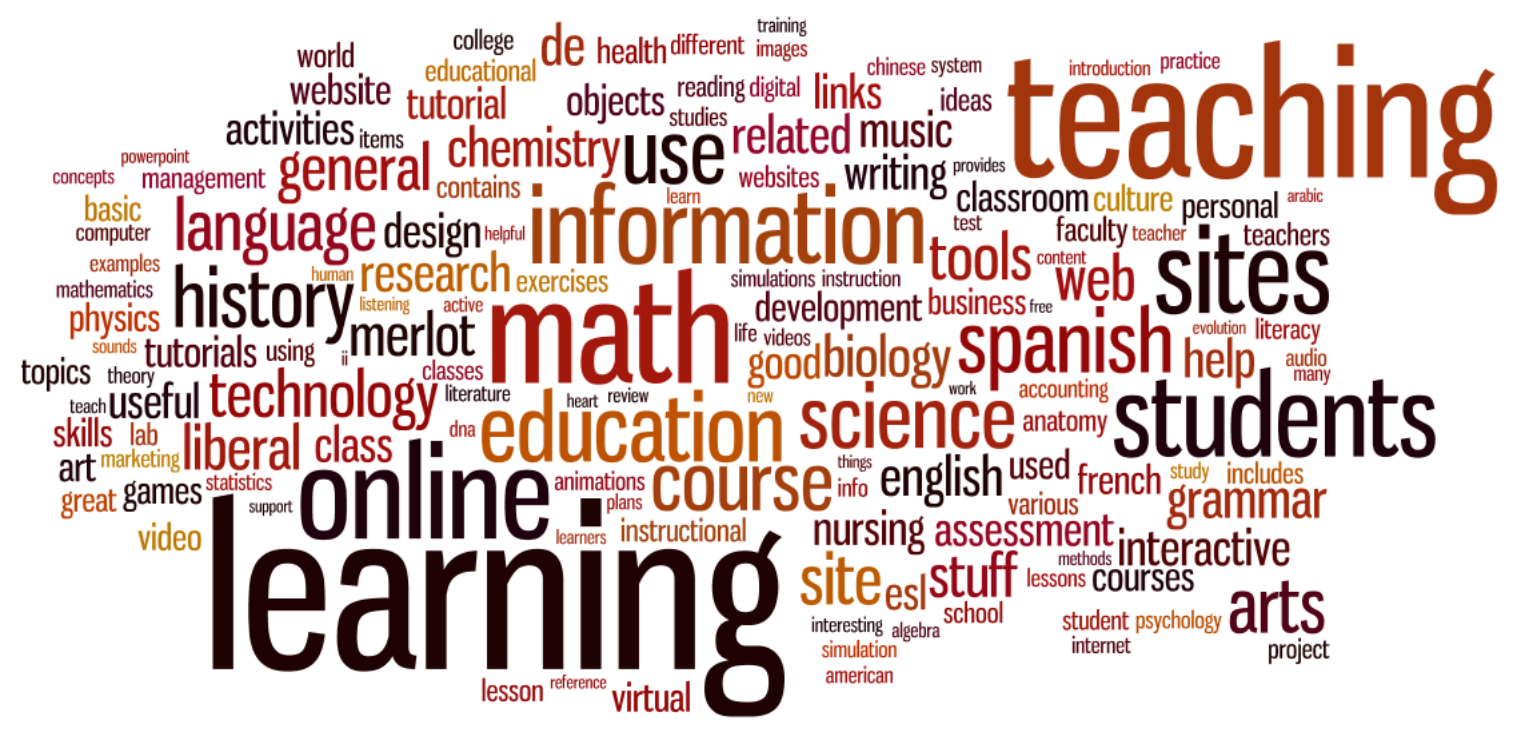

Figure 1. Word Cloud of Bookmark Collections text

The collection number grows over time as well as the number of members creating them (Figure 2). During the past eight years, the number of collections increased from 7,837 to 20,138 , and the number of collection creators increased, as well, from 4,330 to 9,802.

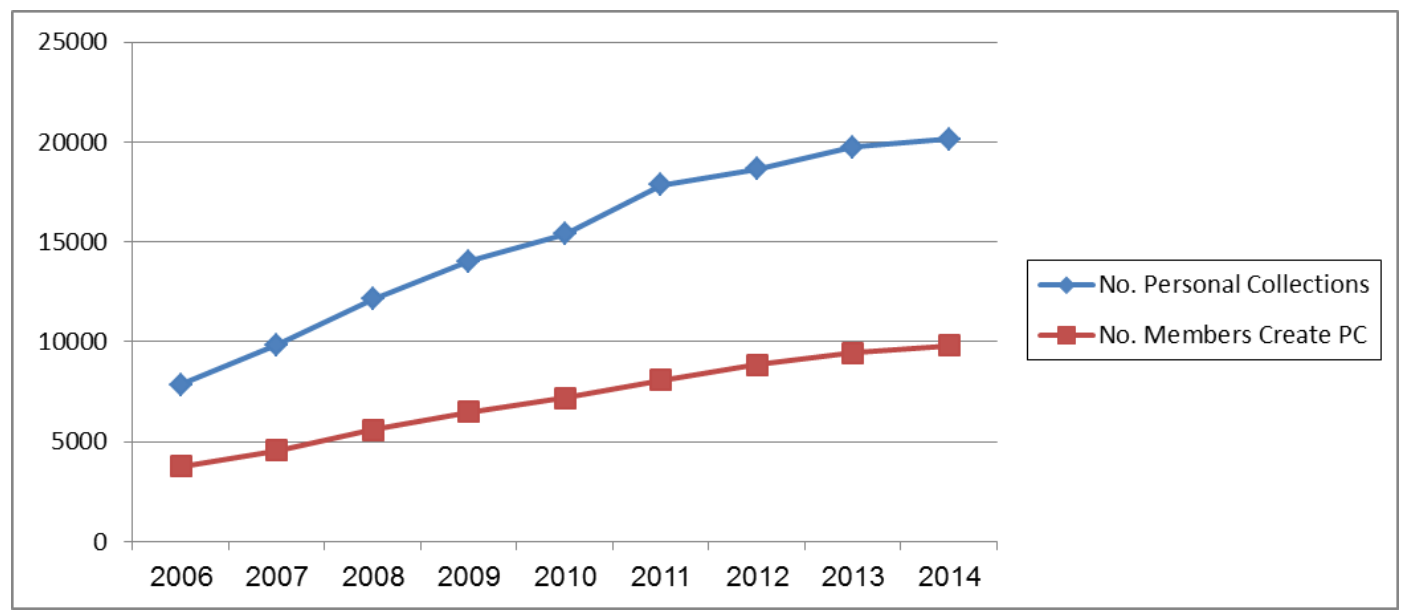

Figure 2. Growth rate of Personal Collections and their creators

\section{The Bookmark Collection Users}

Bookmark Collections have been found to be the most widely used component in MERLOT. More than half $(9,802 ; 57 \%)$ of all 17,071 members that contributed at least one item to the MERLOT repository, created Bookmark Collections. Furthermore, the number of collection creators 
$(\mathrm{N}=9,802)$ was greater than any other contributor type, such as: Comment Writers, Material contributors, Peer Reviewers, Learning Exercise Submitters, and Content Builder Material Submitters.

The affiliation of most of the collection creators is education, science, and technologies (49.7\%); other affiliations are non-profit organizations, corporations and governments. Most of the collection creators are faculty members $(4,482 ; 45.7 \%)$ and students $(2,835 ; 29 \%)$; others are staff members, k-12 teachers, librarians, and content developers.

Many of the creators are active users in MERLOT. Of the 9,802 that created collections, 1,288 members have also contributed materials and peer reviews to the repository, written comments, and submitted learning exercises. It was further found that $95 \%$ of the collection creators have contributed between 1-10 items to the repository (including their collections). The affiliation of this group of collection creators is presented in Table 1.

Table 1

The Affiliation of the Active Groups of Collection Creators $(\mathrm{N}=1,288)$

\begin{tabular}{ll}
\hline Affiliation & Number of Creators \\
\hline Faculty & 739 \\
Student & 244 \\
Teacher (K-12) & 119 \\
Other & 102 \\
Administrator & 55 \\
Librarian & 29 \\
\hline
\end{tabular}

An ANOVA analysis was used to compare the six types of active contributors from the diverse affiliations to determine whether there were significant differences among them. The ANOVA analysis yielded significant differences regarding the intensity of their usage level of contributing materials $[F(5,1282)=4.727, p<0.001]$ and peer reviews $[F(5,1282)=3.789, p<0.005]$ to the repository, as well as sharing content builder materials $[F(5,1282)=2.525, p<0.05]$. No significant differences were found regarding writing comments and submitting learning exercises (Table 2).

Table 2

This work is licensed under a Creative Commons Attribution 4.0 International License. 
ANOVA Analysis for the Six Types of Active Members from Diverse Affiliations $\quad(N=1,288)$

\begin{tabular}{|c|c|c|c|c|c|c|}
\hline & & $\begin{array}{l}\text { Sum of } \\
\text { Squares }\end{array}$ & $d f$ & $\begin{array}{l}\text { Mean } \\
\text { Square }\end{array}$ & $F$ & Sig. \\
\hline \multirow{3}{*}{$\begin{array}{l}\text { No. of materials } \\
\text { contributed }\end{array}$} & Between Groups & 1560853.130 & 5 & 312170.626 & 4.727 & .000 \\
\hline & Within Groups & 84658776.689 & 1282 & 66036.487 & & \\
\hline & Total & 86219629.819 & 1287 & & & \\
\hline \multirow[t]{3}{*}{ No. of peer reviews } & Between Groups & 28.622 & 5 & 5.724 & 3.789 & .002 \\
\hline & Within Groups & 1936.949 & 1282 & 1.511 & & \\
\hline & Total & 1965.571 & 1287 & & & \\
\hline \multirow{3}{*}{$\begin{array}{l}\text { No. of learning } \\
\text { exercises }\end{array}$} & Between Groups & 123.294 & 5 & 24.659 & .702 & .622 \\
\hline & Within Groups & 45040.134 & 1282 & 35.133 & & \\
\hline & Total & 45163.429 & 1287 & & & \\
\hline \multirow[t]{3}{*}{ No. of comments } & Between Groups & 739.337 & 5 & 147.867 & 1.439 & .207 \\
\hline & Within Groups & 131721.656 & 1282 & 102.747 & & \\
\hline & Total & 132460.993 & 1287 & & & \\
\hline \multirow{3}{*}{$\begin{array}{l}\text { No. of content } \\
\text { builder resources }\end{array}$} & Between Groups & 11.971 & 5 & 2.394 & 2.525 & .028 \\
\hline & Within Groups & 1215.479 & 1282 & .948 & & \\
\hline & Total & 1227.450 & 1287 & & & \\
\hline
\end{tabular}

In order to gain more insight into the different types of contributor behavior and locate groups of contributors with the same patterns of activity, Two-Step Cluster Analysis was conducted for the 507 most active contributors. The included variables were: writing comments and peer reviews, as well as sharing his/her learning materials, learning exercises, and contents that were built with the content builder. Three clusters resulted with good cluster quality and a high Silhouette measure of cohesion and separation (Average Silhouette=0.7) as shown in Figure 3. 


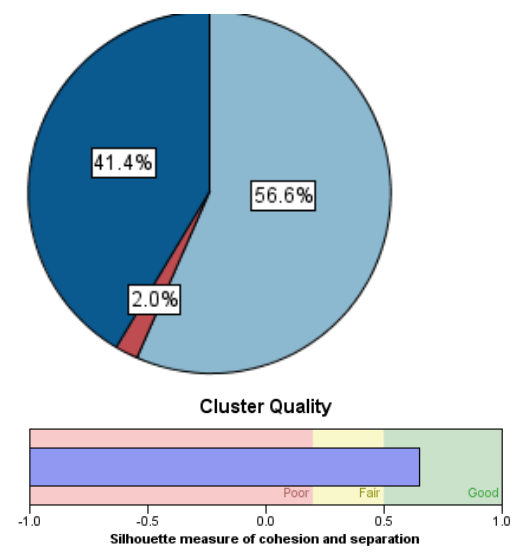

Figure 3. Cluster size and quality
Table 3

Cluster Descriptions [the colors represent the input (predictor) importance]

\begin{tabular}{|l|l|l|l|}
\hline Cluster & 1 & 2 & 3 \\
\hline Size & $\begin{array}{l}56.6 \% \\
(287)\end{array}$ & $\begin{array}{l}2 \% \\
(10)\end{array}$ & $\begin{array}{l}41.4 \% \\
(210)\end{array}$ \\
\hline Comments & 4.66 & 77.9 & 3.74 \\
\hline $\begin{array}{l}\text { Resources } \\
\text { created by } \\
\text { content } \\
\text { builder }\end{array}$ & 0.06 & 5.1 & 0.06 \\
\hline $\begin{array}{l}\text { Peer } \\
\text { reviews }\end{array}$ & 0.29 & 7.9 & 0.08 \\
\hline $\begin{array}{l}\text { Materials in } \\
\text { collections }\end{array}$ & 18.77 & 373.36 & 6.2 \\
\hline $\begin{array}{l}\text { Learning } \\
\text { exercises }\end{array}$ & 0.81 & 16.2 & 0.19 \\
\hline
\end{tabular}

The contributors in clusters 1 and 2 were characterized as faculty members while the contributors in the $3^{\text {rd }}$ cluster were characterized as students. Cluster 2 (2\%) was unique with its high level of activity; the faculty members in this cluster were markedly using the collections and uploaded a large number of materials for various uses and aims (some of the uses and aims will be presented in the next section - Bookmark Collection Uses and Aims). These members shared learning exercises and resources with the community that they created using the content builder. They also sent comments and peer reviews. The contributors in clusters 1 (56.6\%) and 3 (41.4\%) were active as well, while the faculty members (cluster 1 ) were more active in each activity, especially in organizing different materials in their personal spaces.

The ANOVA analysis yielded significant differences among the three clusters $(\mathrm{P}<0.001)$ regarding all activity types as shown in Table 4. 
Table 4

ANOVA Analysis for the Three Clusters ( $\mathrm{N}=507)$

\begin{tabular}{|c|c|c|c|c|c|}
\hline & & $d f$ & Mean Square & $F$ & Sig. \\
\hline \multirow[t]{3}{*}{ No of Bookmarks } & Between Groups & 2 & 2090.945 & 17.528 & .000 \\
\hline & Within Groups & 504 & 119.292 & & \\
\hline & Total & 506 & & & \\
\hline \multirow{3}{*}{$\begin{array}{l}\text { No. of materials } \\
\text { contributed }\end{array}$} & Between Groups & 2 & 11262935.037 & 93.981 & .000 \\
\hline & Within Groups & 504 & 119842.616 & & \\
\hline & Total & 506 & & & \\
\hline \multirow[t]{3}{*}{ No. of peer reviews } & Between Groups & 2 & 293.206 & 113.578 & .000 \\
\hline & Within Groups & 504 & 2.582 & & \\
\hline & Total & 506 & & & \\
\hline \multirow[t]{3}{*}{ No. of learning exercises } & Between Groups & 2 & 1224.024 & 33.854 & .000 \\
\hline & Within Groups & 504 & 36.156 & & \\
\hline & Total & 506 & & & \\
\hline \multirow[t]{3}{*}{ No. of comments } & Between Groups & 2 & 26623.878 & 194.054 & .000 \\
\hline & Within Groups & 504 & 137.198 & & \\
\hline & Total & 506 & & & \\
\hline \multirow{3}{*}{$\begin{array}{l}\text { No. of content builder } \\
\text { resources }\end{array}$} & Between Groups & 2 & 124.487 & 160.429 & .000 \\
\hline & Within Groups & 504 & .776 & & \\
\hline & Total & 506 & & & \\
\hline
\end{tabular}




\section{Material Retrieval/Reuse through the Collections}

The MERLOT repository provides access to 46,870 educational materials in varied disciplines and types. Of those, $29.1 \%(\mathrm{~N}=13,653)$ were reused and integrated in the 20,138 collections. Due to the fact that material can be integrated in more than one collection, a total of 51,164 links to materials were found in all 20,138 collections. Figure 4 presents the distribution of the materials in all 20,138 collections. The collections differ in the number of items in them. There are a significant number of collections which do not include links to materials while others do include links to different materials in large number. The highest number of materials in the collections was found to be 185. In Figure 3 a logarithmic scale (base 10) is presented on the y-axis, since the range of values that was found regarding the number of the collections was very large. The smallest value for the number of collections is 1 , while the largest is 9,447 . The logarithmic scale enables the display of lower value dispersion. The materials represent a variety of disciplines (Science and Technology, Humanities, Business, Education, Social Sciences, Arts, Mathematics and Statistics, Workforce Development, and Academic Support Services) and types (Reference Material, Tutorial, Presentation, Simulation, Collection, Animation, Drill and Practice, Open Textbook, Open Journal-Article, Online Course, Quiz/Test, Case Study, Assessment Tool, Assignment, Learning Object Repository, Workshop and Training Material, Social Networking Tool, Development Tool, and ePortfolio).

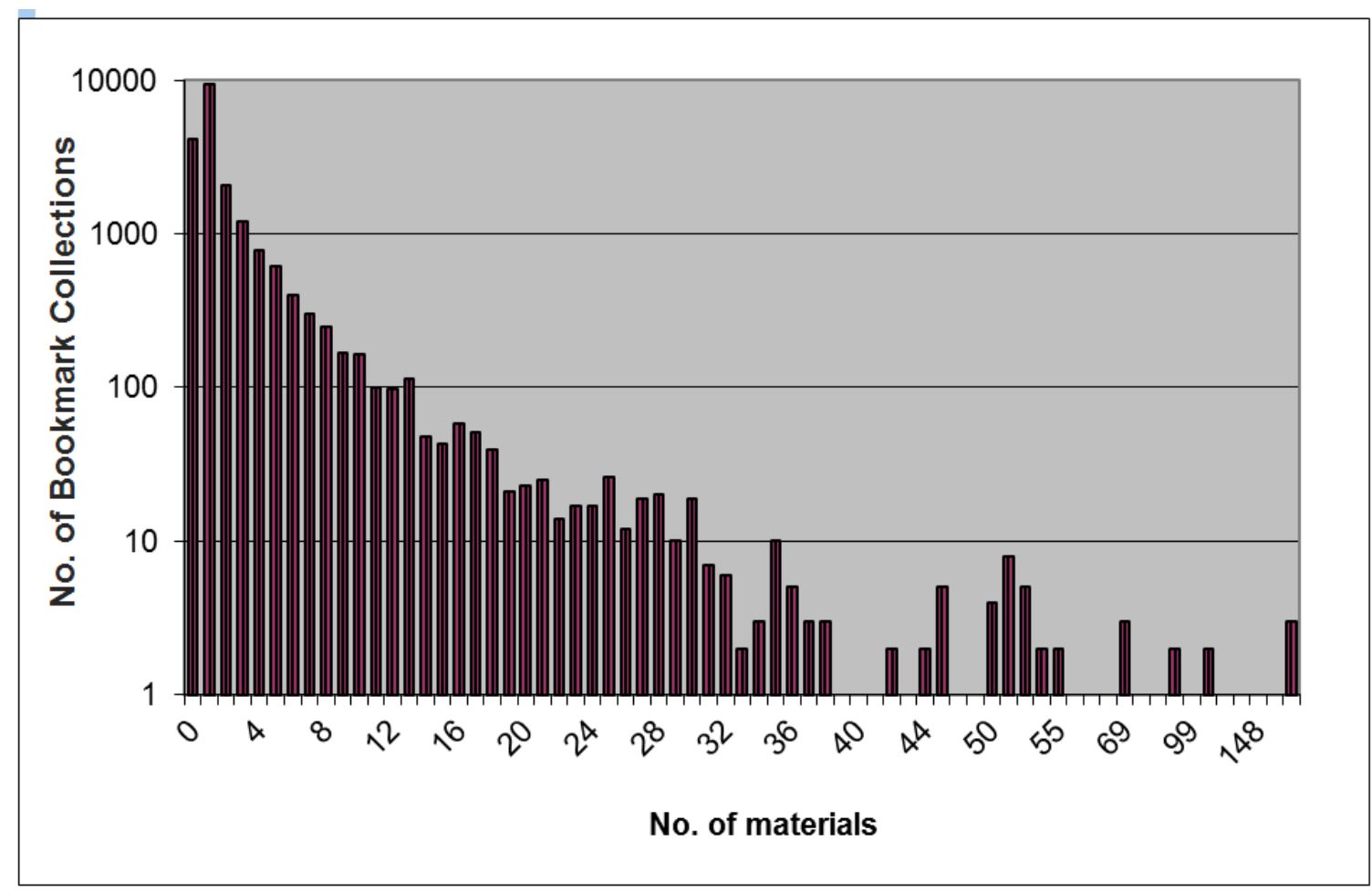

Figure 4. No. of materials in Personal Collections 


\section{Bookmark Collection Uses and Aims}

The findings show that Bookmark Collections are applicable for a variety of uses. In this section various common usages will be presented.

MERLOT members create collections for various uses with diverse goals: for their own teaching use (e.g. my tools, my resources), while allowing others to view and copy; for other users, such as the students in their courses and other students; for teachers of their discipline; for their professional community, etc.

The most common usage was a Bookmark Collection as an assemblage of resources and tools, which support the learning of particular domain skills and their improvement. It is used for rapid detection of these resources and tools at any time and for repeated use in the process of teaching or learning. In these collections, new teaching and learning processes are constructed on the basis of the existing materials that are available. The creator uses materials (OER) which are developed by others and includes them in his/her personal space within the repository. The materials remain in the public domain, yet the construction of the new process takes place in a personal space. Collections also were found commonly as an assemblage of support materials for a course, or as one wrote "Non-text teaching materials - some interactive and possibly relevant resources." To these materials the user added metadata to describe the resource. For example:

"This is an excellent interactive on-line case study of the Cameron Hot Air Balloon factory in Bristol, UK. It covers many aspects of the functional disciplines of business: human resource management, operations, production management, accounting, marketing, etc. It also includes hypertext links to different departments in the ACTUAL FACTORY! The site is illustrated with real photos..." (The Cameron Balloon Factory, Author: University of Bristol, BizEd, Submitter: Ron Purser, 2008).

Another common usage was a Bookmark Collection as a stage (environment) for the presentation of resources and various outcomes for the community. For example, displaying student products or project products, whether they manage and operate them or whether these projects are gathered from the repositories. One example is the Teaching Resources for Ecuador and Peru:

"...the Center for Latin American Studies was awarded Fulbright Hays Group Project Abroad funding to take twelve K-12 teachers to Ecuador and Peru for four weeks. During that time teachers attended seminars, met with local indigenous communities, and visited a variety of cultural sites. From their experiences, teachers developed lesson plans and materials pertinent to their interests. This collection consists of these lesson plans and materials...and Contrasting Cultural 
Values, Diversity in the Andes, Cultural Patrimony, and Andean Textiles" (Teaching Resources for Ecuador and Peru, 2010)

An additional examples are:

"presentation of ELIXR Websites and call for collaborations: "The goal is to create innovative models for the development, sharing and use of disciplineoriented resources which illustrate exemplary teaching practices and which also support faculty with exemplary learning objects to help implement those practices with their students..." (ELIXR Websites in MERLOT, 2011)

"Students Tools": "In Fall 2005, Delgado Community College in New Orleans was flooded as a result of Hurrican Katrina. Faculty and students scattered and were trying to build online resources to continue to offer their classes in the spring of 2006..." (Delgado Community College, 2009)

Furthermore, Bookmark Collections were used for creating and displaying open text books, such as the Community College Open Textbook Collaborative:

"This is a collection of open textbooks currently under consideration for review by the Community College Open Textbook Project (http:// www.collegeopentextbooks.org) of the Community College Consortium for Open Educational Resources" (Community College Open Textbook Collaborative, 2011)

The "Open Math Textbooks (http:// cccoer.wordpress.com)." Bookmark Collections were used for creating and displaying ePortfolios and ePortfolio standards. Examples: Institutional ePortfolio research; A series of white papers on ePortfolios written for Educause Learning Initiative and the EduTools ePortfolio Review Project:

"... EduTools and ePAC International undertook the review of seven ePortfolio products on the behalf of seven partner institutions or systems of institutions... a set of 69 electronic portfolio features were identified and defined by Bruce Landon. Based on those features, reviews were conducted and completed in April 2006. According to the agreement with the partners, the feature set and reviews are now available for public use" (EduTools Project, 2006).

"There is much discussion about showcasing for workforce development, and some states are supporting ePortfolios for their residents." (ePortfolios in Workforce Development, 2009) 
Bookmark Collections were also used for displaying online courses. Examples: "This course offers an introduction to the major themes of Western civilization, many of which have had a profound influence on American society and culture..." (Western Civilization - History course, 2011); or the online courses of the Open Course Library at Washington State-

"These are free, online courses that are part of the Open Course Library at Washington State, a collection of shareable course materials created for faculty to use in their classes. As part of the Open Course Library this content is licensed under the Creative Commons Attribution License which means that you are free to reuse the course in its entirety, edit it and use your own modified version, or pick out only pieces which can be incorporated into your own course, as long as you credit the original author for their work..." (Washington State Board for Community \& Technical Colleges, 2011)

The Carnegie Mellon shared "Open Learning Initiative Courses: These are courses that have been developed by Carnegie Mellon for the Open Learning Initiative (http://oli.web.cmu.edu/openlearning/initiative)" (Carnegie Mellon, 2011). In other cases support material for online courses were displayed.

Bookmark Collections were associated with the websites of 420 courses and were used for publishing the course or contained resources related to the course subject matter. Additional usages included a collection as a space for teachers from diverse disciplines. For example: STARTALK Arabic Collection (2008): "Here are web sites that may be used to engage young learners of the Arabic language, especially those in the STARTALK program" or the Learning to Teach Online (2011): "Free online professional resources for educators who want to develop successful online teaching skills." And yet another usage is a collection for creating and displaying Workshops. For example: 5-minute eClips and Brief Hybrid Workshops (2009): "An 'eClip' is a pre-recording produced as a single computer file. It may include a variety of media elements: sound, images, text, etc..."

\section{Discussion and Conclusion}

The possibility and ability of personal expression in a shared open, global, and public space is needed. Personal spaces allow users to express themselves within the learning and creative process. Users construct, preserve, and present knowledge in a way uniquely suited to their individual patterns of use. Creators of these learning processes can use materials developed by others and include them in their personal spaces within the repository. Personal spaces enable the construction of a unique learning process in private spaces that suits the learner's needs, and therefore, increases user/ member satisfaction. Furthermore, the number of personal spaces (such as Bookmark Collections which are known by their previous name: Personal Collections) for 
learning material has been demonstrated to be highly correlated with quality, since it is positively associated with good materials for every category of discipline, and the rating threshold in which it has presented significant difference (Cechinel et al., 2011). As personal collections are known to be a good predictor of high ratings (García-Barriocanal \& Sicilia, 2009), this is reflecting that items included in many collections are more likely to have high ratings and to be recommended (Sicilia, García-Barriocanal, Sánchez-Alonso \& Cechinel, 2010).

Only members can create Bookmark Collections; however, everyone (MERLOT members or nonmembers) can view and use Bookmark Collections (the new name for Personal Collection) available in MERLOT (Ochoa \& Duval, 2009). All collections are shared with the community; they are completely online, and can be used at any time and any place. The collection can be customized easily and quickly for individual needs without requiring special technical knowledge, and is applicable for a variety of uses. In this study, quite a big community of MERLOT users were found to be very active contributors in the public spaces, as well as in the personal spaces. The use of personal spaces for various needs by this community enhanced the reuse of OER. Furthermore, in addition to the reuse of OER in their personal spaces and sharing them, they were found to be active as a community by writing comments, sharing in learning exercises, and resources that they built using the content builder, as well as doing peer reviews of OER available in the repository. This finding is reinforced alongside the claim that once the community is strong enough, the user-generated collaborative quality instruments such as peer reviews, comments, and rankings can be trusted more to assure the quality of the LO repositories and Computersupported Collaborative Learning (CSCL) environments (Clements, Pawlowski, Manouselis, 2015).

In this paper the usage of Bookmark Collections in the MERLOT repository has been discussed theoretically and empirically evaluated. The findings of this study will help us gain insight into the actual process of PC publication in the MERLOT repository, along with adaptation to other communities connected to MERLOT. Understanding the process of creation and usage of personal spaces within learning object repositories will help the administrator of the repositories to design and plan the technological infrastructure needed to receive, store, and share the published personal spaces, along with adapting to other communities that are connected (in this case MERLOT communities). Policy-makers can also use this analysis to evaluate the best approaches for encouraging contributors to publish their personal spaces. In further study, distribution methods of personal spaces and best practices will be explored in order to better help OER users to organize their resources effectively for various aims and needs. 


\section{References}

Abelson, H. (2008). The creation of opencourseware at MIT. J ournal of Science Education and Technology, 17(2), 164-174.

Cohen, A., Shmueli, E., \&Nachmias, R. (2011). The usage of data repositories: The case of MAOR. Interdisciplinary J ournal of E-Learning and Learning Objects (IJ ELLO), Special Series of Chais Conference 2011 Best Papers, 7, 323 - 338.

Bernstein, S. (2015). OER and the value of openness: Implications for the knowledge economy, Globalisation, Societies and Education 13(4), 471-486.

Bonk, C. J . (2009). The world is open: How web technology is revolutionizing education. San Francisco, CA: J ossey-Bass.

Butcher, N. \& Hoosen, S. (2012). Exploring the business case for open educational resources. Commonwealth of Learning, British Columbia: Vancouver. Retrieved October 21, 2015 from http:// oasis.col.org/ bitstream/handle/11599/57/pub_OER_BusinessCase.pdf?sequence $=1$ \&isAllowed $=\mathrm{y}$

Cannell, P., Macintyre, R., \& Hewitt, L. (2015). Widening access and OER: Developing new practice. Widening Participation and Lifelong Learning, 17(1), 64-72.

Cechinel, C., Sanchez-Alonso, S., \& Garcia-Barriocanal, E. (2011). Statistical profiles of highlyrated learning objects. Computers \& Education, 57(1), 1255-1269.

Clements, K., Pawlowski, J ., Manouselis, N. (2015). Open educational resources repositories literature review - Towards a comprehensive quality approaches framework. Computers in Human Behavior, 51(B), 1098-1106.

Dahl, O. J ., \&Nygaard, K. (1966). SIMULA - An ALGOL based simulation language. Communications of the ACM, 9(9), 671-678.

De Liddo, A. (2010). From open content to open thinking. World Conference on Educational Multimedia, Hypermedia and Telecommunications (Ed-Media 2010), Canada.

The Directory of Open Access Repositories - OpenDOAR. (2015). Growth of the OpenDOAR Database - Worldwide. Retrieved J uly 23, 2015 from http:// www.opendoar.org/ find.php?format=charts 
Downes, S. (2007). Models for Sustainable Open Educational Resources. Interdisciplinary J ournal of Knowledge and Learning Objects, 3, 29-44.

Friesen, N. (2009). Open Educational Resources: New Possibilities for Change and Sustainability. The International Review of Research in Open and Distance Learning, 10(5), 1-13.

García-Barriocanal, E. and Sicilia, M.A. (2009). Preliminary explorations on the statistical profiles of highly-rated learning objects. In: Proc. of the Third Metadata and Semantics Research Conference (MTSR 2009), Springer Communications in Computer and Information Science 46, pp. 108-117.

Hilton, J . L., Lutz, N., \& Wiley, D. (2012). Examining the reuse of open textbooks. International Review of Research in Open and Distance Learning, 13(2), 45-58.

Hilton, J . L., Wiley, D. (2011). Open access textbooks and financial sustainability: A case study on Flat World Knowledge. The International Review of Research in Open and Distance Learning, 12(5), 18-26.

Hilton J . L., Wiley, D., Stein, J ., \& J ohnson, A. (2010). The four 'R's of openness and ALMS analysis: Frameworks for open educational resources. Open Learning: The J ournal of Open, Distance and e-Learning, 25(1), 37-44.

Hylén, J . (2006). Open educational resources: Opportunities and challenges. Retrieved J uly 7, 2014 from http:// www.oecd.org/ dataoecd/5/47/37351085.pdf

The J ORUM Team. (2006). E-learning repository systems research watch. Project Document. Retrieved October 21, 2015 from http://www.jorum.ac.uk/wp-content/uploads/2015/01/Jorum_ELearning_Repository_Systems_Research_Watch_2006.pdf

Malloy, T. E., \& Hanley, G. L. (2001). MERLOT: A faculty-focused web site of educational resources. Behavior Research Methods, Instruments, \& Computers, 33(2), 274-276.

MERLOT. (2013). Multimedia educational resource for learning and on-line teaching website. Retrieved from http:// www.merlot.org/

Monge, S., Ovelar, R., \& Azpeitia, I. (2008). Repository 2.0: Social dynamics to support community building in learning object repositories. Interdisciplinary J ournal of ELearning and Learning Object, 4, 191-204.

Murphy, A. (2013) Open educational practices in higher education: Institutional adoption and challenges, Distance Education, 34(2), 201-217. 
Ochoa, X., \& Duval, E. (2009). Quantitative Analysis of Learning Object Repositories. IEEE Transactions on Learning Technologies, 2(3), 226-238.

Pirkkalainen, H., \& Pawlowski, J. (2013). Global social knowledge management: From barriers to the selection of social tools. Electronic J ournal of Knowledge Management, 11(1), 3-17.

Sicilia, M. A., García-Barriocanal, E., Sánchez-Alonso, S., \& Cechinel, C. (2010). Exploring userbased recommender results in large learning object repositories: the case of MERLOT. Procedia Computer Science 1, 2859-2864.

The Open University of Israel (2014). Opening the treasures of the mind: Open access to textbooks and study materials. Retrieved J uly 7, 2014 from http:// ocw.openu.ac.il/eng_files/english.html

Qian, G. (2010) The web as PLE: Perspective from educational technology and internet psychology, ICETC2010: Proceeding of the 2nd International Conference on Education Technology and Computer, pp.V1-262-V1-266.

Razavi, M.N., and Iverson, L. (2006) A grounded theory of information sharing behavior in a personal learning space. CSCW '06: Proceedings of the 20th anniversary conference on Computer supported cooperative work, pp. 459- 468.

Reisman, S. (2009). Using learning objects to affect educational outcomes. Computer, 42(8), 102104.

Taylor, J . C. (2007). Opencourseware futures: Creating a parallel universe. E-J ournal of Instructional science and technology, 10(1), 1-9.

World Forum of UNESCO. (2002). UNESCO promotes new initiative for free educational resources on the Internet. Paris. Retrieved J uly 7, 2014 from http://www.unesco.org/education/news en/080702 free edu ress.shtml

Wiley, D., Green, C., \& Soares, L. (2012). Dramatically bringing down the cost of education with OER: How open education resources unlock the door to free learning. Retrieved J uly 7 , 2014 from http:// www.educause.edu/library/resources/dramatically-bringing-downcost-education-oer-how-openeducation-resources-unlock-door-free-learning

Wiley, D. (2007). On the sustainability of open educational resource initiatives in higher education. Paper commissioned by the OECD's Centre for Educational Research and Innovation (CERI) for the project on Open Educational Resources. OECD 2007. 
Personal Spaces in Public Repositories as a Facilitator for Open Educational Resource Usage

Cohen, Reisman, and Sperling

(C) Cohen, Reisman, and Sperling

\section{Athabasca University $\mathbf{a}$}

(c)

This work is licensed under a Creative Commons Attribution 4.0 International License. 